\title{
Research In Chinese Farmers' Appeal And Government Response From The Perspective Of Network Politics Interaction
}

\author{
Ru-min LYU ${ }^{1, *}$, Rui-Fang-ZHAO ${ }^{2}$ \\ ${ }^{1}$ Shandong Institute of Business And Technology \\ ${ }^{2}$ Shandong Institute of Business And Technology \\ ${ }^{*}$ Corresponding author.Email: lvrm03@sohu.com
}

\begin{abstract}
This paper uses LDA(Latent Dirichlet Allocations) analysis, multiple correspondence analysis and other methods to analysis 16140 samples of network politic interaction texts to analysis Chinese rural and agriculture problems. The author focus on the Chinese farmers' appeal one the network through the most authoritative media of RenMinWang, and use government responses. The results show that the farmers will choose different appeal strategies according to their appeal type in the online political interaction, and the government will quote more policy provisions on land acquisition and demolition in its reply. Different themes lead to different styles and strategies of response. This study provides a reference for Chinese agricultural policies and farmers interest expression mechanism.
\end{abstract}

Keywords: Agricultural issues, appeal strategy, network politics, government response

\section{RESEARCH BACKGROUND}

Network politics has been more and more popular in Chinese media in recent years. With the progress of modern communication technology, Chinese government have established network platforms for the public to appeal their right and publish their opinions on the internet and mobile media, such as Microblog, TV, Weichat and so on. In 2006, the Chinese government established the Local Leaders Message Board(LLMB) on the platform of RenMinWang (a popular media established by the Chinese government), which set up the provincial and city leaders' political inquiry board. The public can choose different local leaders message boards to post messages, and express their claims through the network. In addition, some provinces in China have established supervision mechanism, which stipulates that local leaders must reply to public messages. "LLMB" is the only official authoritative political platform in China, which provides a data basis for the study of Chinese government services and public demands.
"Three rural issues" stands for China rural, agriculture and farmer problems. For many years, the "three rural issues" is emphasized as the most important problem. Since 2004, the three rural issues has been emphasized as the first problem for the government. China still has 550 million people living in rural areas. Finding and solving the problems of rural areas, agriculture and farmers in time is of great significance for ensuring China's food security, promoting the development of modern agriculture and maintaining rural stability.

The issue of agriculture, rural areas and farmers has always been an important topic in academic circles. Wen Tiejun and other scholars defined "agriculture, rural development and farmers' income" in the early stage. In the 21 st century, some scholars summarized it as "food security, urban and rural equality and farmers' empowerment". For a long time, the academic circles have different definitions of the three rural issues. The confusion of the concept leads to different causes and solutions ${ }^{[1]}$. So, what are the problems in China's rural areas in the new century, how do farmers express their needs, and how do government departments deal with 
them. All these are worthy of our discussion. This study selects the "local leaders message board(LLMB)" of the "three rural" part, take the public appeal and government response text as the analysis object, the author explores the manifestation and solution of China's agricultural problems from the perspective of the interaction between the government and farmers in the network.

\section{LITERATURE REVIEW}

\section{1. specific areas of three rural issues}

The problems of agriculture, rural and farmers are the general name of the problems of agriculture and farmers in China. This concept is widely used in Chinese academic area and government departments. As early as 1996, Wen Tiejun put forward the issue of agriculture, rural areas and farmers in his article ${ }^{[2]}$. Later, this concept has been widely used in the media, academia and government documents in China. However, there are still many controversies about which aspects the three rural issues refer to. Li Changping put forward in 2000 that "farmers are really bitter, rural areas are really poor, and agriculture is really dangerous", which is considered as a representative summary of the three rural issues ${ }^{[3]}$. In the new century, Wen Tiejun redefined the three rural issues as: protection of farmers' rights and interests, sustainable and stable rural development, and agricultural ecological security. There are different opinions on the definition of the three rural issues. Some scholars try to divide the three rural issues from the specific performance of the rural issues. For example, Wang Yanmei summarized the eight issues of farmers' demands: (1) the implementation of policies to benefit farmers; (2) land expropriation and compensation; (3) farmers' social security; (4) rural arbitrary charges; (5) rural environmental pollution; (6) rural infrastructure (7) the implementation of rural land contract policy (8) the violation of discipline and rules by rural Party members and cadres ${ }^{[4]}$. In this study, we use the concept of agricultural issues to replace the three rural issues.

\section{2. research on the interests of farmers}

There are also many literatures about the farmers' demands from the perspective of farmers' active demands. For example, Yang Caiyi believes that the demands of farmers mainly include political rights, economic interests and social security, and three areas. Some scholars pointed out that the problem of farmers is to start around the interests of farmers in the final analysis $^{[5]}$. And the distribution of farmers' interests is mainly the product of rural policies. As Yu Jianrong said, "the struggle of farmers according to law is often directly related to the central and local policies in rural areas" ${ }^{[6]}$. In China, farmers have been weak in political participation and lack of ways to express their interests. But with the development of E-government in China, the way of farmers' expression of demands increases. The local leadership message board (LLMB) of people's network also sets up the "three rural areas" to provide the platform for people to express their demands to the government. Lu Shenghua and others' research shows that, in the aspect of the demands of land expropriation, the paper uses the text analysis method of big data to put forward the strong demand of farmers for the justice of results, and also points out the awakening of farmers' rights consciousness ${ }^{[7]}$.

Although many scholars have made different division on the three rural issues, most of them are based on the investigation of different regions, lack of national big data, depicting the horizontal and vertical development process of farmers' interests.

\section{3. research on network political interaction}

In the 21st century, the network and media have made great progress. The development of network political platform provides a new field for the public to express their demands, and also provides a platform for the government to refer to the public opinions. According to the way of interaction between the government and the people on the Internet, some scholars put forward four types of interaction between the government and the people, namely: azalea mode, mandarin duck mode ${ }^{[8]}$, ostrich mode and queen bee mode. In the process of interaction between the government and the public, both the government and the public realize that the network is conducive to the expression of interests and can ensure the efficiency of government's decision-making, so both sides actively interact and jointly promote "e-democratization". Numerous studies have shown that in online politics, people's demands are strategic, and people often use collective discourse to express their demands, that is, to expand their own interests to the village collective or a wider range, so as to gain the attention of the government ${ }^{[9]}$. There are also studies that show that in the process of people's appeal, rational, logical and emotional characteristics will affect their satisfaction with asking more about politics.

In addition, government departments also pay more attention to the collective appeal of the public. The response of the Chinese government to the public opinion on the Internet is in line with the pressure response model. In terms of the content and quality of government response, most of the existing studies think that government response lags behind, response content is mechanical and so on ${ }^{[10]}$. At present, there are few studies on the quality of government response in the process of network politics in China. On the issue of agriculture, rural areas and farmers, Chinese farmers appeal through the network platform, and the 
government responds to it. Through the analysis of the texts of both sides, we can not only clarify the coverage of agriculture, rural areas and farmers, but also see the strategies of China's grassroots rural governance. This study attempts to use descriptive statistics, text mining, clustering and other methods to analyze China's three rural issues based on the data of people's daily.

\section{RESEARCH METHODS AND DATA DESCRIPTION}

This paper investigates the data of "people's network local leaders message board", which has been the only national political platform since its trial operation in 2006. This study collected the text data of Internet politics in 31 provinces of China since 2014. This study focuses on the interaction between the government and the public in the online political inquiry. Therefore, we choose the samples that contain both the public's political inquiry and the government's response in the online political inquiry text. For those data that only ask for the government's political inquiry, but the government departments do not give the response, this study is regarded as missing data and is not included in the scope of analysis. In the process of data collection, the self-made Python crawler program is used. In the process of data collation, the word segmentation tool is Jieba library, the text emotion analysis tool is snownlp library, and the topic analysis tool is sklearn library. After word segmentation, the stop words are cleaned up by using the stop words list of Harbin Institute of technology. The final valid data is 16140 .

Table 1 Province distribution of LLMB data

\begin{tabular}{|c|c|c|c|}
\hline Province & N & Province & N \\
\hline Henan & 2707 & Yunnan & 208 \\
\hline Sichuan & 2492 & Jilin & 193 \\
\hline Gansu & 2180 & Heilongjiang & 178 \\
\hline Anhui & 953 & Chongqing & 162 \\
\hline Shaanxi & 887 & Jiangxi & 123 \\
\hline Hebei & 866 & Ningxia & 117 \\
\hline Shandong & 820 & Jiangsu & 98 \\
\hline Hubei & 587 & Hunan & 86 \\
\hline Henan & 2707 & Fujian & 73 \\
\hline Sichuan & 2492 & Qinghai & 62 \\
\hline Liaoning & 548 & Hainan & 56 \\
\hline Guangxi & 510 & Zhejiang & 40 \\
\hline Guizhou & 487 & Shanghai & 20 \\
\hline Shanxi & 415 & Xinjiang & 12 \\
\hline Inner Mongolia & 395 & Tibet & 3 \\
\hline Tianjin & 310 & Fujian & 73 \\
\hline Beijing & 291 & Qinghai & 62 \\
\hline Guangdong & 261 & Hainan & 56 \\
\hline Liaoning & 548 & & \\
\hline Guangxi & 510 & & \\
\hline
\end{tabular}

From the perspective of the time trend of the appeal of the network politics of the three rural issues, with the increase of years, the number of appeal texts is also gradually increasing. Starting from 660 copies in 2014, the number has increased year by year, with the largest number of 7085 copies in 2020.

Table 2 Year distribution of LLMB data

\begin{tabular}{|c|c|c|c|}
\hline Year & N & Year & N \\
\hline 2014 & 660 & 2019 & 3783 \\
\hline 2015 & 618 & 2020 & 7085 \\
\hline 2016 & 912 & 2014 & 660 \\
\hline 2017 & 956 & 2015 & 618 \\
\hline 2018 & 2126 & & \\
\hline
\end{tabular}

\section{RESEARCH RESULTS}

The political demands of farmers are mainly closely related to their own interests. The academic circles have given many divisions on the problems of farmers' demands, but they are lack of empirical data support. In the process of network politics, people express their own interests, express their opinions, and put forward consultation through text content. Through the analysis of the appeal text, we can conclude which aspects of the main interests of farmers in China are focused on. In this study, the unsupervised learning method and the topic model method in sklearn are used to classify the political texts.

\section{1. classification of the theme of farmers' demands}

Firstly, the key words cluster method is used to select the 16140 government texts with the highest importance through the inverse document frequency (TFIDF value). These keywords are used to replace the original political text. The key words database is classified and analyzed by hierarchical clustering. Through hierarchical clustering, we can see that farmers' demands on agriculture, rural areas and farmers can be summed up into six major ones Class, further use the theme model, to extract the theme of the political text.

After classification, there are 6 topics. Topic 1 is land acquisition compensation. In the political text, 2156 are about the demands of such issues. In this kind of farmers' demands, there are many words such as demolition, compensation, resettlement, land acquisition, etc.

Topic 2 is about rural public infrastructure, which can be considered as people's livelihood travel, such as road construction, tap water, life, travel, etc.

Topic 3 is the demand of agriculture planting development. There are 1832 such demands, among which the key words are subsidies, policies, poverty alleviation, breeding, agriculture, etc. 
Topic 4 can be considered as the social security of farmers, among which, the following keywords appear more frequently, such as household registration, children, the elderly, low-income insurance, applications and so on.

Topic 5 is related to the confirmation of rural land contract, among which, land, cultivated land, contract, confirmation of rights and other keywords appear more frequently. There are 3735 such appeals.

Topic 6 is about the construction of new countryside, or the problem of rural housing. It is corresponding to the needs of housing conditions.

\subsection{Multiple correspondence analysis of network politics}

In this study, we classify farmers' political inquiry and government response according to different types, and explore the process and mechanism of government people interaction in network political inquiry through multiple correspondence analysis.

The variable operation method is as follows:

X1_Pelevel:administrative level of appeal, provincial level $=1 ;$ municipal level $=2$

X2_Ptype: topic type of appeal, represents 6 topic see in table 3

X3_Psenti: emotional tendency of appeal text, emotional value is between $0-1$, emotional value $>=0.5$ is positive, emotional value $<0.5$ is negative

X4_PReal: whether use the real name to ask the government, the farmers' appeal text contains "My name is", "I'm ", the text is marked as $1=$ real name, the appeal text contains the Chinese mainland mobile phone number marked $1=$ real name, the rest is $2=$ non real name.

Y1 Rday: the number of days between government responses, represents the number of days when farmers' demands are extracted and the date of government responses are subtracted. In terms of natural days, the number of days within 30 days is marked as less than one month, and the number of days over 30 days is marked as more than one month

Y2 Rplcy: whether there are policies in the government's reply, represents the reply text of the government, it is marked as having policy if it contains 《》, and no policy if it does not.

Y3_RTel: does the government's reply include mobile phone numbers and phone numbers, represents the reply text contains the Chinese mainland mobile phone number marked $1=$ real name, the rest is $2=$ non real name.
Y4 Rlength: represents the length of government reply text. If the length exceeds 300 words, it is marked as long text, otherwise it is marked as short text

Through the above operational method, the above variables are used for analysis, and the results are as follows:

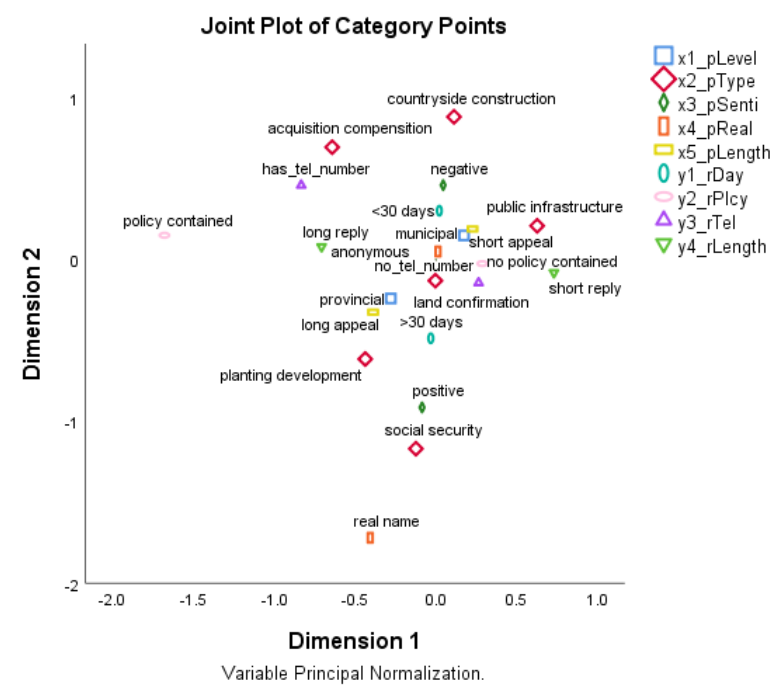

Figure 1 Multiple correspond analysis of the farmers' appeal and government response text

As can be seen from the above figure, the government's response to land acquisition and demolition is highly targeted. For farmers' demands of land acquisition and demolition, the government's reply is longer, and it is more inclined to quote the policy text, and leave the contact information of relevant departments. This shows that in the current problems of agriculture, rural areas and farmers in our country, the government departments of our country have allocated more attention to the problem of land acquisition and demolition of farmers, and have shown more patience in dealing with the demands of farmers.

On other issues, farmers' demand for strategic performance is more obvious. For example, on the issue of people's livelihood travel, farmers are more inclined to appeal to municipal leaders. On the issue of contract confirmation, farmers are more inclined to express their appeal to provincial leaders. It can be seen that the purpose of farmers' demands is clear. On the basic issues of people's livelihood, municipal leaders tend to know more about the local situation, so the faster the problem is solved. On the issue of land contract confirmation, it often involves the national policies, so it is more likely to express demands to the superior leaders. On the issue of social security, farmers are more inclined to use real names and positive emotional expression. Farmers hope to increase the possibility of solving their own problems in this way. This shows that the demands of farmers are rational and their goals are relatively clear. 


\section{CONCLUSION}

The main conclusions are as follows:

1. from the perspective of the demands of network politics, the three rural issues in China can be discussed from the way of farmers' interests. At present, there are six main demands of farmers' expression through the network, which are land acquisition, demolition, planting development, contracting and confirmation of rights, people's livelihood travel, housing planning and social security.

2. the political demands of farmers are rational. In the process of network politics, farmers have a clear understanding of the ability of resource mobilization of governments at all levels in China. Under different demands, farmers will adopt different demands strategies. For example, when seeking the interests of social security, farmers will use their real names to make demands, increase credibility and attract the attention of government departments.

3. the attention distribution of government departments is influenced by the strategies of farmers' demands, but it has independence. In the three rural issues, the government departments of our country pay more attention to the land acquisition and demolition, respond more timely, and tend to use policy provisions to guide farmers to protect their own interests reasonably and legally.

This study focuses on the theme types of the three rural issues from the perspective of network politics, and the strategies and logic of the interaction between the government and the people in the process of the network asking of the three rural issues. The results show that the "people's network local leadership message board" as the platform, the establishment of rational communication between the government and farmers, and with the development of time, message board participation is also increasingly high, which provides an effective way for China to achieve "electronic democracy". To explore the interaction between the government and the people in the three rural issues will help to solve the agricultural problems and realize the agricultural modernization.

\section{AUTHORS' CONTRIBUTIONS}

Please see the article for additional information, including other authors, author contributions and affiliations, financial disclosures, funding and support, etc.

\section{ACKNOWLEDGMENTS}

Fund Project: Shandong soft science project "analysis of influencing factors of Internet users' satisfaction in Internet politics" (2019rkb01306)
Author: Lu Rumin, male, lecturer, School of Public Administration, Shandong University of Business and Technology, research area: network public opinion analysis, public policy evaluation, digital governance. Email:1vrm03@sohu.com.

Zhao Ruifang, female, lecturer, School of Public Administration, Shandong University of Business and Technology, research area: public welfare and charity.

\section{REFERENCES}

[1] Ye Jingzhong, "three rural issues": exaggerated academic concept and its limitations [J]. Southeast academic, 2018, 000 (005): 112-123.

[2] Wen Tiejun. Two basic contradictions in the second step of rural reform [J]. Strategy and management, 1996 (3): 111-114.

[3] Li Changping: I tell the truth to the premier, Guangming Daily Press, 2002, P. 20.

[4] Wang Yanmei. Eight kinds of issues have become the hot spot of farmers' appeal [j]. People's hearts, 2017, 000 (003): 17-17

[5] Yang Caiyi. The current problems and ways of realizing the interests of farmers in China $[\mathrm{J}]$. Legal system and society, 2017 (23).

[6] Yu Jianrong. An explanatory framework for the current activities of safeguarding farmers' rights [J]. Sociological research, 2004

[7] Lu Shenghua, Yao Yuting, Wang Hui. Farmers' demands in Land Expropriation: big data analysis based on "message board of local leaders" [J]. Agricultural economic issues, 2020 (7): 58-68

[8] Weng Shihong, ye Xiaoyun. Logical analysis of local government's decision-making response under the network participation -- Taking Ningbo PX incident as an example [J]. Journal of public administration, 2013,10 (04): 26-36 + 138.

[9] Li Feng, Meng Tianguang. Strategic political interaction: the use of netizens' political discourse and government response mode [J]. Journal of Wuhan University (humanities edition), 2016,69 (5): 119-128, 3.

[10] Li Huilong, Yu Junbo. Responsive traps of Digital Government Governance: Based on the investigation of "message boards of local leaders" in the three eastern provinces [J]. E-government, 2019 (03): 72-87. 